\title{
Larval control of Anopheles (Nyssorhinchus) darlingi using granular formulation of Bacillus sphaericus in abandoned gold-miners excavation pools in the Brazilian Amazon Rainforest
}

\author{
Allan Kardec Ribeiro Galardo ${ }^{[1]}$, Robert Zimmerman $^{[2]}$ and Clícia Denis Galardo ${ }^{[1]}$
}

[1]. Divisão de Zoologia, Instituto de Pesquisas Científicas e Tecnológicas do Estado do Amapá, Macapá, AP. [2]. Florida Medical Entomology Laboratory, University of Florida, Vero Beach, Florida, U.S.A.

\begin{abstract}
Introduction: Use of a Bacillus sphaericus based mosquito larvicide was evaluated as an intervention for malaria vector control at a mining site in Amapá, Brazil. Impacts on larval and adult densities of the primary vector Anopheles darlingi were measured over the course of a 52 week study period. Methods: In Calçoene, State of Amapá, gold mining activity occurs in 19 mining sites in gold-miners of Lourenço. Large pools are formed in mining sites and naturally colonized by Anopheles darlingi. During one year, the impact of applications of VectoLex ${ }^{\circledR}$ CG to these larval sources was evaluated. Applications of $20 \mathrm{~kg} / \mathrm{ha}$ were made as needed, based on 10 immature $\left(3^{\text {rd }}, 4^{\text {th }}\right.$ instars and pupae) surveillance of health and established thresholds. Results: One hundred percent initial control was observed $48 \mathrm{~h}$ after each treatment. The pools received from $2-10(5.3 \pm 1.6)$ treatments during the year. The average re-treatment interval in productive pools was $9.4 \pm 4.3$ weeks. During weeks 3-52 of the study, mean density of late stage larvae was $78 \%$ and pupae were $93 \%$ lower in the treated pools than in untreated pools $(\mathrm{p}<0.0001$, $\mathrm{n}=51)$ while reduction of adult mosquitoes was $53 \%$ in comparison to the untreated area during the last five months of the study, which were the rainy season $(\mathrm{p}<0.001)$. Conclusions: VectoLex ${ }^{\circledR}$ CG reduced immature Anopheles darlingi infestation levels during the entire study period, and reduced adult mosquito populations during the rainy season.
\end{abstract}

Keywords: Anopheles darlingi. Bacillus sphaericus. Gold-miners. Malaria.

\section{INTRODUCTION}

Anopheles darlingi is the main vector of parasite of malaria in Brazil. Malaria transmission is primarily restricted to the Amazon region, and is prevalent in some states where settlements for gold mining have been established ${ }^{1}$. In the State of Amapá $14.4 \%$ of the malaria cases in 2008 were associated with gold mining, $78 \%$ of which occurs in the municipality of Calçoene where the gold mining district of Lourenço ${ }^{2}$ is located.

The National Malaria Control Program (PNCM) guidelines are focused in early detection and treatment of cases, indoor residual spray (IRS) and more recently, insecticide treated nets (ITN), as key components of the strategy to reduce malaria transmission. In-house adult mosquito control strategies are central components of malaria vector control, but may not provide complete protection against transmission by exophagic and exophilic vectors including the An. darlingi in the Brazilian

\footnotetext{
Address to: Dr. Allan Kardec Ribeiro Galardo. Divisão de Zoologia/IEPA. Rodovia JK, Km 10, s/nº, Fazendinha, 68912-250 Macapá, AP, Brasil.

Phone: $55963212-5353$

e-mail: allan.galardo@iepa.ap.gov.br

Received 22 May 2012

Accepted 22 February 2013
}

Amazon $^{3-6}$. Control of malaria vector populations through larval source management (LSM) may substantially reduce adult malaria vector populations providing protection in addition to adult control measures ${ }^{7}$.

In Brazil, LSM is largely focused on environmental management such as drainage and filling of larval sources ${ }^{8}$. However, physical measures are not always feasible, leaving many larval sources uncontrolled. Examples of such situations include fish ponds, residual mining pools, water reservoirs and natural wetlands. In these situations, the use of microbial larvicides such as Bacillus sphaericus (Bs) and Bacillus thuringiensis israeliensis (Bti) may be useful components of LSM. The use of these larvicides has been shown to control anopheline mosquito populations, and reduce malaria transmission in Africa and Latin America ${ }^{7-14}$. Extended control of An. darlingi larvae has been observed in fish ponds in Peru with VectoLex ${ }^{\circledR}$ CG, a 50 Bs International Toxin Units (ITU) granular formulation of B. sphaericus 2362 strain ABTS-1743 ${ }^{15}$. Residual control also has been observed in natural breeding sites of An.albimanus in Colombia ${ }^{16}$, and of An. braziliensis, An. marajoara and An. triannulatus in Venezuela ${ }^{17}$.

This study evaluated the impact of regular applications of VectoLex ${ }^{\circledR} \mathrm{CG}$ on $A n$. darlingi larval sources in a gold mining area in the municipality of Calçoene, State of Amapá, Brazil. The study measured larval development and adult population dynamics of An. darlingi in treated and untreated areas and de influence of rain precipitation in the density of larval and adult mosquitoes. 


\section{METHODS}

\section{Study area}

The municipality of Calçoene was $227 \mathrm{~km}$ north of Macapá, the capital of Amapá State (Figure 1). The climate was tropical and rainy, with a mean annual precipitation of $3,069 \mathrm{~mm}$ and average temperature of $25.6^{\circ} \mathrm{C}$, with $75 \%$ relative humidity. The study site was in the village of Lourenço, which is one of the 27 villages in the municipality that has extensive gold mining activity ${ }^{18}$. Gold mining occurred in 19 mining areas (Figure 2), where gold extraction was performed through excavations and jets of water provided by pressure pumps. During the process of gold extraction large excavation pools were formed around the mining site. When these pools were abandoned, they were colonized by mosquito larvae, including An. darlingi, which was responsible for the maintenance of the malaria transmission among the mines' workers, living near these pools (FUNASA, unpublished data).

Two mining sites were selected for the study - Novo Astro (treatment) and Nova Lataia (untreated control). The Novo Astro site was chosen for treatment, because it was an area with a history of a high incidence of malaria ${ }^{2}$.

\section{Entomology surveys}

Adult An. darlingi populations were monitored by outdoor and indoor mines capture sessions using human landing catches and hand-held aspirator. These surveys were performed once a month at both untreated control and treatment sites for three consecutive days from $18 \mathrm{~h}$ to $21 \mathrm{~h}$. Four trained entomology technicians of the Medical Entomology Laboratory of the Scientific and Technology Research Institute of Amapá, performed the captures in pairs, outdor and indoor the mines.

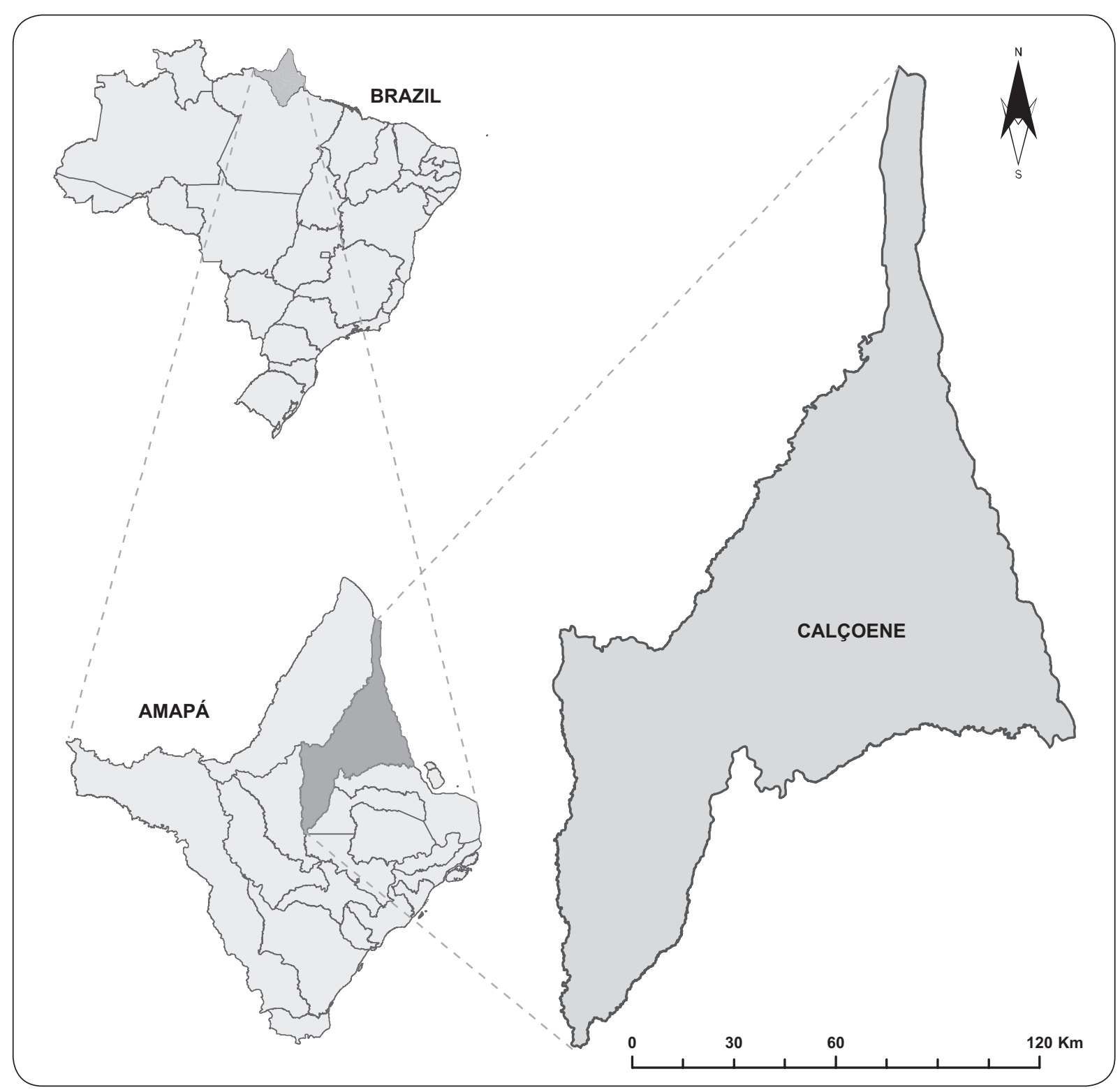

FIGURE 1 - State of Amapá and the municipality of Calçoene. 


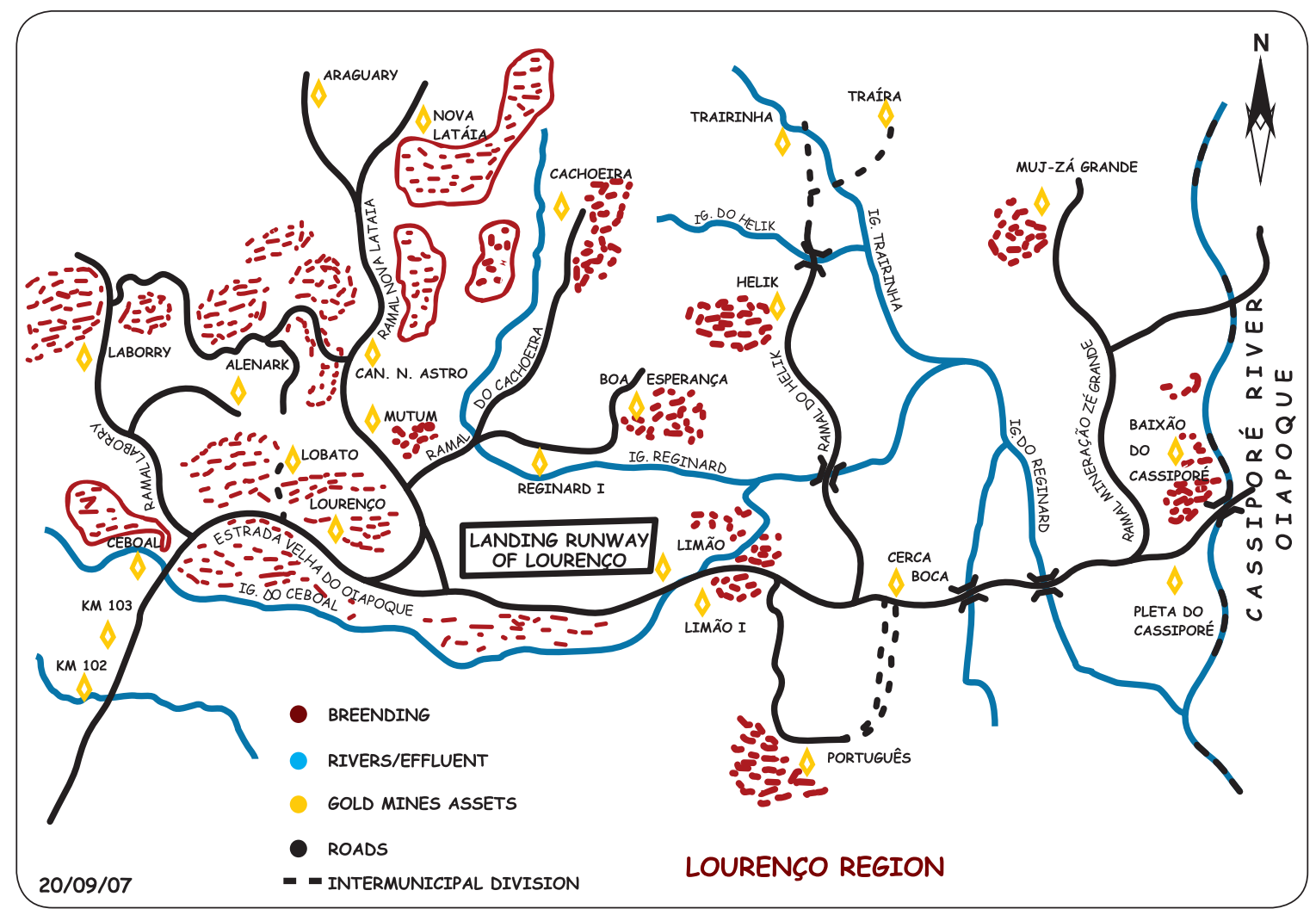

FIGURE 2 - Drawing of the gold mining region of Lourenço in the municipality of Calçoene, State of Amapá. Yellow spots indicate active mining sites, and the red spots are Anopheles sp. larval sources. The study sites are represented in the box, Nova Lataia and Novo Astro.

Each technician followed a specific method of work and a predetermined schedule with rotation of sites to minimize bias. Mosquitoes were collected with a manual suction aspirator before they initiated a blood meal, and were transferred to the laboratory in labeled moisture chambers. Live specimens were anesthetized with ethyl acetate for further identification. The species of subgenus Nyssorhinchus were identified employing the taxonomic keys of Faran \& Linthicum ${ }^{19}$ modified by Voorham, and Consoli \& Oliveira ${ }^{20}$

All 23 larval source in abandoned gold-miners excavation in the area, were evaluated individually, and records were kept of the larval survey results on the treatment date and post treatment evaluation ( $48 \mathrm{~h}$ post treatment). Larval surveys were performed weekly one day per week in the 52 weeks, from $6 \mathrm{~h}$ to $9 \mathrm{~h}$ using a 5L dipper. Pond borders were marked every $5 \mathrm{~m}$ with wooded sticks. These locations were sampled with nine dips per location during each sampling throughout the study period. Ponds with perimeter greater than $100 \mathrm{~m}$ were sampled at a maximum of 20 locations. The number of immature Anopheles (larvae and pupae) collected in each dip was counted and recorded by instar stage (first instars - L1, second instars - L2, third instars - L3, fourth instars - L4, and pupae).

\section{Larval source treatment}

Treatments were made using VectoLex ${ }^{\circledR}$ CG, manufactured by Valent BioSciences Corp., at the rate of $20 \mathrm{~kg} / \mathrm{ha}$. The product was applied by hand, except for one large pool which was treated with a motorized backpack blower (Guarany $\left.{ }^{\circledR}\right)$.
The pools were retreated when late instars (L3 and L4), and pupae were detected in numbers greater than 10 per sampling during weekly larval surveys.

\section{Data analysis}

Weekly counts of immature anopheline mosquitoes in 23 treated and untreated ponds were analyzed by life stage categories including early instars (L1 and L2), late instars (L3 and L4), and pupae. The average number of each stage collected in treated ponds $(n=9)$ and untreated ponds $(n=2)$ was calculated weekly. The means of weekly averages in treated and untreated ponds were analyzed across weeks 3 to $52(\mathrm{n}=51)$ of the study using both a z-test and an ANOVA in order to compare the number of immature stages collected during the entire treatment period. Adult landing collections in treated and untreated areas were similarly compared across time applying ANOVA to monthly collections in the dry season (May to December, $\mathrm{n}=7$ months) and wet season (January to May, $\mathrm{n}=5$ months). Correlation of adult population densities and rainfall in treated and untreated areas were evaluated using the correlation function of the MS Excel data pack (Pearson's correlation coefficient).

\section{Ethical considerations}

All the participants of the research team signed a Term of Informed Consent. The project was approved by the Ethic in Research Committee of Institute of Scientific Research and Technology of the State of Amapá/AP under the code number 003-2008. 


\section{RESULTS}

\section{Larval source treatments}

From May 2008 to May 2009, 23 pools were selected and evaluated at the untreated site, Nova Lataia. Only nine pools at the Novo Astro site (area under treatment) produced Anopheles larvae during the study period. The other sites dried out during the study or were not productive due to pollution from mining activities, inhibiting mosquito development.

The number of treatments and consumption of the Bacillus sphaericus formulation is presented in Table 1 . Of the 23 pools monitored only nine required treatment. All treatments resulted in $100 \%$ larval reduction $48 \mathrm{~h}$ post-treatment. Most treated sites had received initial treatment by week 2 of the study. Based on the established treatment thresholds and surveillance, an overall average treatment interval in the active sites following initial treatment was $9.4( \pm 4.3)$ weeks. Active sites required an average of $5.3 \pm 1.6$ treatments during the year. Sites 2 and 3 received nine treatments during the year and the remaining sites required between two and seven treatments.

TABLE 1 - Larval sites and amount of VectoLex CG used at the Lourenço gold mine area

\begin{tabular}{lcccc}
\hline Site & $\begin{array}{c}\text { Area } \\
\left(1,000 \mathrm{~m}^{2}\right)\end{array}$ & $\begin{array}{c}\text { VectoLex } \\
\mathrm{CG}(\mathrm{Kg})\end{array}$ & $\begin{array}{c}\text { Number } \\
\text { of treatments }\end{array}$ & $\begin{array}{c}\text { Total } \\
(\mathrm{Kg})\end{array}$ \\
\hline Untreated 1 & 75 & - & - & - \\
Untreated 2 & 5.2 & - & - & - \\
2 & 1.3 & 2.6 & 9 & 23.4 \\
3 & 12 & 24 & 9 & 216 \\
5 & 3.5 & 7 & 7 & 49 \\
6 & 2.4 & 4.8 & 5 & 33.6 \\
7 & 2.1 & 4.2 & 4 & 16.8 \\
8 & 3.8 & 7.6 & 4 & 30.4 \\
20 & 7.5 & 15 & 2 & 30 \\
21 & 0.5 & 1 & 6 & 6 \\
23 & 1.15 & 2.3 & 10 & 23 \\
\hline Total & 39.5 & 68.5 & 5.3 & 428.2 \\
\hline
\end{tabular}

\section{Entomological outcomes}

The impact of the VectoLex ${ }^{\circledR}$ CG treatment is shown in Figure 3. The mean number of all stages was significantly lower in treated vs. untreated sites by both ANOVA $(p<0.0001)$ and $z$-test $(\mathrm{p}<0.0001)$. Immature densities tended to increase in the untreated pools, and decrease in the treated pools. The total number of all immature stages of anophelines was $80 \%$ lower in treated pools compared to untreated pools. The number of L1 and L2 larvae collected was 73\% lower, the number of L3-L4 larvae was 78\% lower, and pupae were 93\% lower in treated compared to untreated pools. Pupal densities were highly suppressed in the treated pools from February to May 2009. In February 2009, the percent reduction in pupal density reached $100 \%$ and remained near zero for the remainder of the study.

During monthly mosquito capture sessions, two malaria vectors species were predominant all year, An. darlingi presented in Figure 4. The number of adults captured in monthly surveys was positively correlated by Pearson's correlation with rainfall in the untreated area $(+0.52$ correlation), correlated with rainfall in the treated area (-0.17 correlation coefficient). Reduction of the adult mosquito population in the Novo Astro site was detected during the suppression in the rainy season from January to June 2009, when a 53\% $(\mathrm{p}<0.001)$ reduction in the number of An. darlingi captured was maintained throughout this period, in comparison with the untreated site, Nova Lataia. This observation is in agreement with the observed reduction of the production of the larvae and pupae shown in Figure 3.

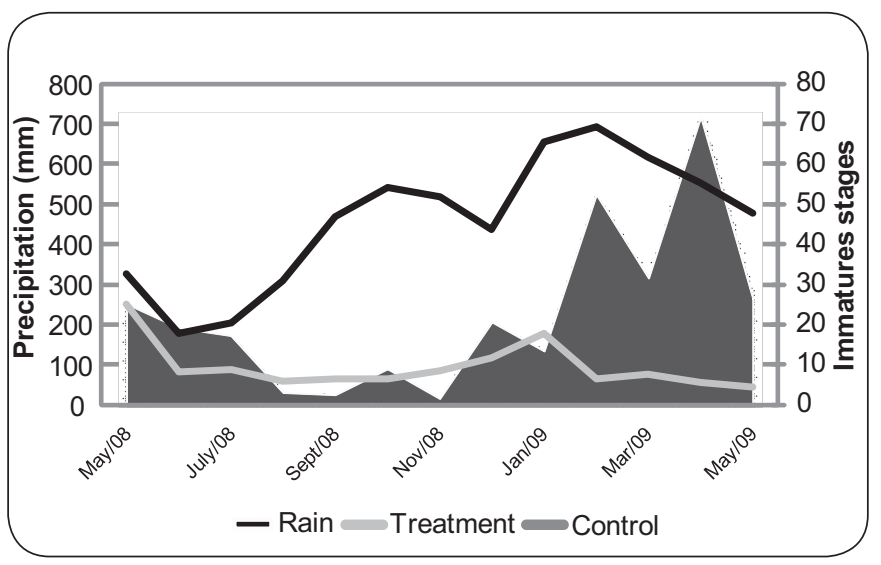

FIGURE 3 - Rainfall and number of immatures stages collected in the two areas studied in the community of Lourenço, Calçoene, State of Amapá.

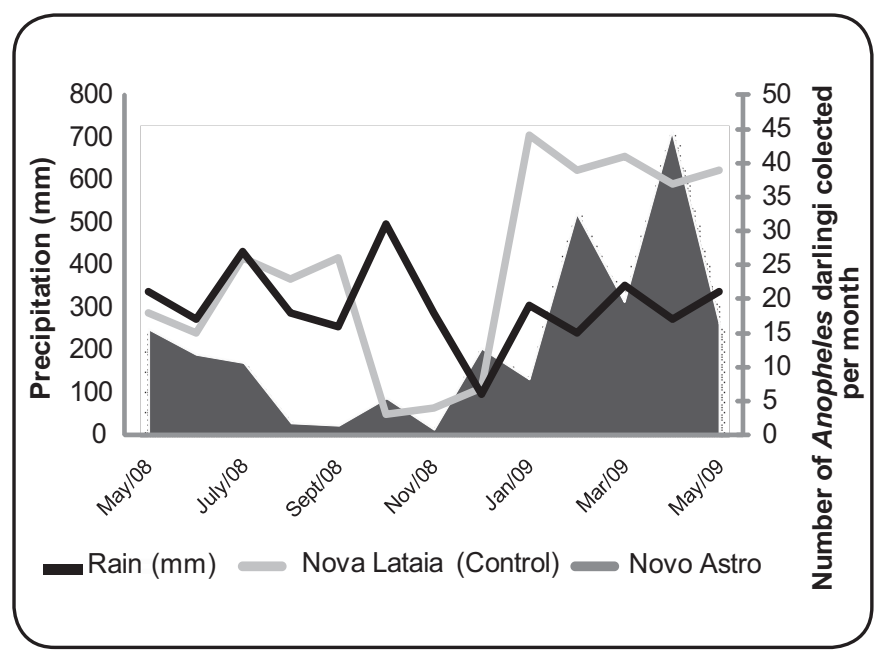

FIGURE 4 - Rainfall (mm) and Anopheles darlingi collected in the community of Lourenço, Calçoene, State of Amapá. 


\section{DIscussion}

This year-long study is the first work to evaluate the efficacy of surveillance-based Vectolex ${ }^{\circledR}$ CG applications for control of An. darlingi population densities over time. The results showed that it is feasible to maintain control of An. darlingi population densities in a gold mining area. Late instar and pupal reductions indicated that after the third week of treatment, a significant level of control of immature life stages was reached and maintained throughout the study period. Also, beginning in February 2009 the production of pupae in the treated sites was suppressed to near zero; demonstrating that these larval sites were unproductive in the rainy season while the untreated control sites were highly productive.

The low mean number of required treatments per pool and the 9-week average re-treatment interval indicated that residual efficacy was achieved following VectoLex ${ }^{\circledR}$ CG treatment. This result is in agreement with results obtained following VectoLex ${ }^{\circledR}$ CG treatment of fish ponds for control of An. darlingi in Peru ${ }^{15}$, where a residual control of late instars was observed for 45 days with a single application at the rate of $20 \mathrm{~kg} / \mathrm{ha}$, same rate used in this study. Similar results were obtained in Colombia, where a $92 \%$ reduction in pupae of An. albimanus was observed 33 days after treatment ${ }^{16}$, and in the studies with anopheline vectors from Venezuela ${ }^{17,21}$, which showed an efficacy of $\sim 80 \%$ from 28 to 90 days after a single application of VectoLex ${ }^{\circledR}$ CG. The positive correlation of An. darlingi abundance with rainfall in the untreated control sites suggests that the onset of the rainy season played a determinant role in the increase Anopheles abundance. This is in agreement with a recent study conducted in State of Amapá on the relationship between anophelines abundance and rainfall ${ }^{22}$. However, in the treated site, the negative correlation between rainfall and number of mosquitoes collected indicated that the LSM strategy reduced the adult vector population even during the rainy season. Similar strategies have been proven successful in Tanzania ${ }^{14}$ and Kenya ${ }^{7}$ where the reduction in entomology inoculation rates (EIR) and malaria transmission was demonstrated through the integration of microbial larvicides use with other interventions in large scale programs. The suppression of Anopheline populations demonstrated by the results obtained in this trial, suggest that sequential applications of VectoLex CG can be a powerful integrated vector management (IVM) tool for reducing human-vector contact in this environment.

It can be concluded that it is feasible to maintain control on An. darlingi population densities in gold mining areas with a LSM program based on the use of microbial larvicides.

\section{ACKNOWLEDGMENTS}

The authors would like to thank team GIS Division and Technical entomology of the Centro de Pesquisas Zoobotânicas e Geológicas of the Instituto de Pesquisas Cientificas e Tecnológicas do Estado do Amapá Aderbal A. Santana,
Francisco Redivaldo A. Souza, Jorge P. Duarte and José Claudio C. Mendes. We also thank to Paulo de Tarso R. Vilarinhos for advising on the protocol and contributing to the edits of the article.

\section{CONFLICT OF INTEREST}

The authors declare that there is no conflict of interest.

\section{FINANCIAL SUPPORT}

This study was partially supported by Valent BioSciences Corporation.

\section{REFERENCES}

1. Oliveira-Ferreira J, Lacerda MVG, Brasil P, Ladislau JLB, Tauil PL, Daniel-Ribeiro CT. Malaria in Brazil: an overview. Malaria J 2010; 9:115.

2. Ministério da Saúde. Sistema de Informações de Vigilância em Saúde. Malária. Notificação de casos. Relatório. Brasília: Ministério de Saúde; 2010.

3. Klein TA, Lima JBP. Seasonal distribution and biting patterns of Anopheles mosquitoes in Costa Marques, Rondonia, Brazil. J Am Mosq Control Assoc $1990 ; 6: 700-707$.

4. Zimmerman RH. The ecology of malaria vectors in the Americas and future direction. Mem Inst Oswaldo Cruz 1992; 87:371-383.

5. Conn JE, Wilkerson RC, Segura MNO, Souza RTL, Schlichting CD, Wirtz R, et al. Emergence of a new Neotropical malaria vector facilitated by human migration and changes in land use. Am J Trop Med Hyg 2002; 66:18-22.

6. Zimmerman RH, Galardo AKR, Lounibous LP, Arruda M, Wirtz R. Bloodmeal Hosts of Anopheles species (Diptera: Culicidae) in a Malaria-Endemic Area of the Brazilian Amazon. J Med Entomol 2006; 43:947-956.

7. Fillinger U, Ndenga B, Githeko A, Lindsay SW. Integrated malaria vector control with microbial larvicides and insecticide-treated nets in western Kenya: a controlled trial. Bull World Hlth Organ 2009; 87:655-665.

8. Ministério da Saúde. Secretaria de Vigilância em Saúde. Programa Nacional de Prevenção e Controle da Malária. Brasília: Ministério da Saúde; 2003.

9. Barbazan PT, Baldet F, Darriet H, Escaffre D, Djoda T, Hougard JM. Impact of treatments with Bacillus sphericus on Anopheles populations and the transmission of malaria in Maroua, a large city in a savannah region of Cameroon. J Am Mosq Control Assoc 1998; 14:33-39.

10. Fillinger U, Knols BGJ, Becker N. Efficacy and efficiency of new Bacillus thuringiensis var. israelensis and Bacillus sphaericus formulations against Afro-tropical Anophelines in Western Kenya. Trop Med Int Hlth 2003; 8:37-47.

11. Moser JB, Ramírez X, González JE, Herrera M. Evaluación de la efectividad de Bacillus sphaericus contra larvas de Anopheles aquasalis Curry (Diptera: Culicidae) en criaderos naturales del estado Sucre, Venezuela. Entomotropica 2002; 17:1-5.

12. Fillinger U, Lindsay SW. Suppression of exposure to malaria vectors by an order of magnitude using microbial larvicides in rural Kenya. Trop Med Inter Hlth 2006; 11:1-14.

13. Majambere S, Lindsay SW, Green C, Kandeh B, Fillinger U. Microbial larvicides for malaria control in The Gambia. Malaria J 2007; 6:76.

14. Geissbühler Y, Kannady K, Chaki PP, Emidi B, Govella NJ, Mayagaya V, et al. Microbial Larvicide Application by a Large-Scale, Community-Based Program Reduces Malaria Infection Prevalence in Urban Dar Es Salaam, Tanzania; PLoS One 2009; 4:e5107.

15. Berrocal E, Carey C, Rodriguez L, Calampa C, Valdivia L. Residual effect of Bacillus sphaericus - VectoLex ${ }^{\circledR}$ CG for the control of Anopheles darlingi in Iquitos, Peru. J Am Mosq Control Assoc 2000; 16:305.

16. Suarez MF, Morales CA. Impact of Bacillus sphaericus (Vectolex® CG) in the control of Anopheles albimanus and Culex spp. in Buenaventura, Colombia. J Am Mosq Control Assoc 1999; 15:407. 
17. Moreno JE, Acevedo P, Martínez A, Sanchez V, Petterson L. Evaluación de la persistencia de una formulación comercial de Bacillus sphaericus en criaderos naturales de anofelinos vectores de malaria en estado Bolívar, Venezuela. Bol Malariol Sal Amb 2010; 50:109-117.

18. Couto AA, Calvosa VS, Lacerda R, Castro F, Santa-Rosa E, Nascimento JM Controle da transmissão da malária em área de garimpo no Estado do Amapá com participação da iniciativa privada. Cad Saúde Pública 2001; 17:897-907.

19. Faran ME, Linthicum KJ. A handbook of the Amazonian species of Anopheles (Nyssorhynchus) (Diptera: Culicidae). Mosquito Systematics 1981; 13:1-81.

20. Consoli RA, Oliveira RL. Classificação das Principais Espécies de importância Sanitária. In: Consoli RA, Oliveira RL, editors. Principais Mosquitos de Importância Sanitária no Brasil. Rio de Janeiro: FIOCRUZ; 1994. p. 17-92.
21. Berti MJ, Gonzáles JE. Evaluación de la efectividad y persistencia de una nueva formulación de Bacillus sphaericus contra larvas de Anopheles aquasalis Curry (Diptera: Culicidae) en criaderos naturales del estado Sucre, Venezuela. Bol Malariol Sal Amb 2004; 44:21-27.

22. Galardo AKR, Zimmerman RH, Lounibos LP, Young LJ, Galardo CD, Arruda M, et al. Seasonal abundance of anopheline mosquitoes and their association with rainfall and malaria along the Matapi River, Amapá, Brazil. Med Vet Entomol 2009; 23:335-349. 